\title{
Verdad, drama y filosofía en el Banquete de Platón
}

\author{
Truth, drama and philosophy in Platon's Symposium
}

\author{
JEREMÍAS CAMINO'
}

Resumen: En el siguiente artículo, nos proponemos indagar sobre la personalidad dramática que Platón imprimió a alguno de sus personajes, a través del análisis de sus discursos. Junto a ello, se manifestará la aparición diferenciada del filósofo, y de cómo es que este elude los problemas dramáticos que envuelven a los no-filósofos, a partir del distinto interés, comportamiento y comprensión. Sostendremos nuestra interpretación sobre la base de que todos los discursos que conforman el Banquete son verdaderos, donde "verdad" será entendida tal como Heidegger la comprendió dentro de su interpretación de la filosofía de Platón y Aristóteles, esto es, en tanto desocultamiento.

Palabras Clave: verdad; drama; ontología; filosofía platónica.

Abstract: In the following article, we propose to inquire into the dramatic personality that Plato imprinted on some of his characters, through the analysis of his discourse. Along with this, the differentiated appearance of the philosopher will be manifested, and how it is that he avoids the dramatic problems that surround non-philosophers, based on the different interest, behavior and understanding. We will sustain our interpretation on the basis that all the discourses that make up the Symposium are true, where "truth" will be understood as Heidegger understood it within his interpretation of the philosophy of Plato and Aristotle, that is, as disclosure.

Key Words: truth; drama; ontology; Platonic philosophy.

Cómo citar: Camino, J. (2021). Verdad, drama y filosofía en el Banquete de Platón. Cuadernos Filosóficos, 18. https://doi.org/10.35305/cf2.vil8.132

Publicado bajo licencia Creative Commons Atribución-SinDerivadas 4.0 Internacional [CC BY-ND 4.0] (c) (1) $\odot$

Fecha de recepción: 14/10/2021

Fecha de aprobación: $21 / / 2 / 2021$

\section{Presentación}

\section{I.I. Objetivo del trabajo y aclaraciones}

En lo que sigue, nos proponemos explorar la relación entre drama y filosofía en el Banquete de Platón. Para ello sostendremos que, más allá de la discusión sobre si este simposio contiene o no elementos históricos, Platón ha intentado plasmar una real 
"personalidad" a sus personajes. Escribimos "personalidad" para mantener una reserva sobre este término: intentando desligarlo de connotaciones de la psicología moderna, con él designaremos al carácter, los intereses explícitos o no y los problemas que afectan a los participantes del diálogo. Anticipamos, también, que es a este conjunto al que resumimos el sentido de la palabra "drama", que obviamente simplifica dicho término, en el cual, usualmente, está connotada una mayor cantidad de elementos que hacen a la composición literaria. ${ }^{2} \mathrm{La}$ razón de esta simplificación se hará entendible cuando se exponga el método escogido.

Ahora bien, esta lectura se desarrolla sobre lo que se podría tomar como una hipótesis: que cada discurso que compone al Banquete es verdadero. El punto clave aquí es entender correctamente el concepto "verdad" en la filosofía de Platón. Para ello, en el primer apartado, en el que tratamos sobre el método que sigue este trabajo, luego de consideraciones generales sobre el Banquete, expondremos el significado de verdad que retoma los análisis que hiciera Heidegger sobre la filosofía de Platón y Aristóteles en las décadas del veinte y del treinta. Sobre la base de lo desarrollado allí, nos abocaremos a estudiar, ya en el segundo apartado, algunos encomios seleccionados, buscando manifestar la personalidad del encomiasta. Finalmente, en el tercer apartado, analizaremos el discurso de Sócrates en pos de presentar qué es lo que hace ser a un filósofo y cómo es que se diferencia de quienes no lo son, en cuanto a comportamiento, comprensión e intereses.

\section{I.2. Método de aproximación}

Con la noción de método referimos al acceso al objetivo planteado, en dos sentidos: I. Acceso como aquel elemento de la obra que conduce correctamente hacia el objetivo; 2. Acceso como aquello que hay que atravesar para alcanzarlo efectivamente. Nuestra propuesta es que ambos sentidos son satisfechos por el lógos. A continuación, explicaremos por qué y detallaremos cómo es así.

Luego de que los invitados hayan comido, en 176e8-9, Erixímaco, habiéndose autoproclamado simposiarca, dice cuál será la manera en que continuará el simposio: "[que] hoy estemos en mutua compañía a través del lógos"3. En otras palabras, es el lógos el que reúne y determina la manera en que los personajes presencian conjuntamente. Pero, ¿qué

2 "Drama" en sentido abarcador contendría, además de lo indicado, el espacio de desarrollo, la época en que transcurre, el ritmo en que se desenvuelve, los interludios o interrupciones, los movimientos, etc.

3 Todas las citas del diálogo son traducciones propias del texto griego de la edición oxoniense de J. Burnet. Todas han sido cotejadas con la traducción al español de Ludueña (Platón, 2015) y la francesa de Brisson (Platón, 2007). 
significa lógos? Antes de pasar a la especificación de la propuesta de Erixímaco, es pertinente ubicarlo en su categoría general que bien enfatizó María Isabel Santa Cruz: esto es, un lógos sympotikós (201 I, p. 13). En este artículo, ella ofrece el siguiente conjunto de características de los simposios griegos (p. 13-4, ibid.): A) el papel central del juego en tanto "exhibición de una habilidad poética no profesional" de cada personaje que, así, "rivaliza entre si" y hace del lógos sympotikós un agón; B) la "búsqueda de recreación y gratificación"; C) la "demostración competitiva" de cada convivo con el fin de "proteger y mejorar su imagen y temor a perderla"; y D) el "despliegue disciplinado de pasiones individuales y colectivas". Excepto A), el resto hace relevante la presencia de la intención de cada personaje, la que se muestra a través del lógos, según la forma impresa que asevera A). La centralidad del lógos es aún más patente por cuanto, como también señala correctamente la autora, Platón elige focalizarse prioritariamente, de todo lo que hace al banquete, en el "intercambio de palabras y escuchas recíprocas y bien ordenadas. La palabra sobresale, pues, sobre los otros elementos, por sobre el alimento y aun por sobre el vino" (p.16).

Dentro de ese contexto, la propuesta específica de Erixímaco es el ti legómenon, el contenido, a saber: el encomio a Eros. Robin (1938, pp. XXXI-XXXII) y Ludueña (20I5, p. XII), en los estudios introductorios a sus traducciones respectivas del Banquete, concuerdan en que Platón usa encomio indiferenciado de épainos, pues se ofrece un homenaje o una celebración de alabanzas de algo; Ludueña, además, señala que también son alabadas las obras del objeto encomiado, en tanto manifestación de su naturaleza. Brisson adiciona a ello la consideración de Aristóteles sobre el encomio, esto es, que es un elogio con reglas, por las que "se comienza definiendo la naturaleza del ser sobre el que se hace el elogio, y luego se consideran los beneficios que se deben derivar de esta naturaleza" (2007, p. 38). Así, cuando cada uno de los invitados realiza su lógos, manifiesta cierta comprensión suya respecto de lo que es Eros y de cómo está relacionado con la vida humana, a través de sus acciones propias. Todos terminan de una forma semejante, aproximadamente así: "por todo lo dicho, Eros es el más hermoso y venerable dios, importante para la vida humana en tales y cuales respectos (por la virtud, la felicidad, la convivencia ciudadana, la amistad, etc.)".

Lógos, entonces, se caracteriza por cuatro aspectos: ser el modo principal de comparecencia de los personajes, ser relación agónica entre ellos, ser comprensión de lo que se habla, y ser lo dicho mismo. De estas cuatro, la comprensión aparece teniendo un papel destacado, ya que podría tomarse como elemento común (cuanto menos en la obra Banquete). Esto, en principio, se puede entender a partir de que, en una reunión como es un banquete, a la comparecencia no la puede determinar el silencio, pero tampoco la expresión no regida por 
algún entendimiento sobre lo tematizado ${ }^{4}$; además, quien entra en una competencia agónica necesita ofrecer una comprensión por la que valga la pena competir. Así, el lógos en tanto comprensión es el elemento de acceso para el objetivo del trabajo.

El procedimiento que aquí seguimos, pues, es un análisis del encomio que ofrecen algunos personajes. A través del modo en que cada uno entiende a Eros, de aquello que enfatiza, los ejemplos que utiliza, los giros discursivos y la forma o "estilo" que tiene su discurso, se refleja de algún modo aquellos elementos dramáticos por los que indagamos. Contrariamente a lo que se esperaría, esto no se justifica por una teoría literaria, que resultaría extemporánea al diálogo platónico, sino por una orientación filosófica, esto es: sobre la base de la verdad. Sostenemos que todos los encomios son verdaderos. La cuestión está en entender qué significa este concepto, porque si se lo toma como una correlación con los hechos, se caería en un absurdo. Pero, ese no es su significado en la filosofía de Platón. Siguiendo algunas obras de Heidegger, en particular Platon: Sophisthes (1992) y Logik. Die Frage nach der Wahrheit (1976), alétheia en Platón es desocultamiento. En lo siguiente, desarrollaremos la interpretación heideggeriana en la que se muestra la vinculación entre lógos, alétheia y einai, que no sólo sustenta filosóficamente la construcción literaria del Banquete, sino que además resulta pertinente para comprender algunas particularidades que presenta el diálogo.

En la filosofía platónica, alétheia (verdad) en tanto desocultamiento es un estado, o, en otras palabras, es un modo de estar en el estricto sentido de ser. Algo está desoculto significa que está presente, que está mostrado. Lo presente o mostrado es el ón en tanto es (Heidegger, 1992, p. 8). Por ello, Heidegger afirma que, en la filosofía platónica, la verdad no sólo es un modo de ser (1976, p. 190; 1992, p. 17), sino que ser y verdad son indistintos. La diferencia nominativa radica en que la verdad designa la apertura del ente en tanto mostrado, lo que significa que el desocultamiento es la manera en que el ente se da. Esto es importante señalarlo, ya que el ente humano trata con el ente en general a través de tal apertura, de tal desocultamiento. Una de las formas del humano tratamiento es el lógos y Heidegger estableció que, al igual que los demás tratamientos, la función del lógos es ser aletheúein, desocultante. Cuando el lógos desoculta al ente lo hace presente en tal o cual respecto, y, presentar algo en tal o cual respecto es mostrarlo comprensivamente (=mostrar algo en tanto algo). Esto es

4 De los estudios que hemos citado, todos acuerdan en estos dos puntos. Es clara la excepción: Aristodemo estuvo, pero no habló; esto nos obliga a admitir la primera diferencia: asistir no es comparecer (no en sentido eminente). Por otro lado, están los otros invitados que han pronunciado discursos, pero no han sido recordados. Esto nos obliga a la segunda diferencia: el sentido de lo dicho, no siempre es valedero (de lo contrario, hubiera valido el recuerdo). 
justamente lo que hacen los personajes del diálogo: presentar a Eros comprendido en tal o cual respecto.

Pero, queda aún algo más. La función aletheúein del lógos no sólo muestra aquello que es tematizado (el ti legómenon), sino que también muestra al que enuncia (legómenon). El ente humano se hace presente a través del lógos - lo que constituye el sentido de synousía del simposio. La pregunta que nos resulta importante establecer para los fines del trabajo es la siguiente: ¿de qué manera se muestra aquel que hace un encomio? $Y$ la respuesta es, simplemente, que la doble mostración del lógos incumbe una forma que es común a ambas partes (lo tematizado y el que habla). Cada personaje es lo que su discurso demuestra. Por ello, es que afirmamos que todos los encomios son verdaderos y que cada uno de ellos es un signo de quien porta y exhibe el lógos, lo cual importa para nuestro método.

Debe tomarse la precaución de que, aunque aquella relación se sostenga sobre el desocultamiento, ello no significa que cada personaje se descubre en sentido contemporáneo. Pues, el descubrir contemporáneo es evidenciar algo, un ser resaltado de manera obvia y despejada de todo factor que vaya en contra de su esclarecimiento. En ese sentido resulta ser el fundamento de las constataciones científicas. Nuestro análisis discursivo y caracterológico no presentará un conjunto de caracteres que el lector podrá constatar, evidenciar o cotejar, en un sentido paralelo a otros trabajos de Filosofía Antigua, como es el de Arturo P. Bernabé al hacer un registro minucioso de los significados de la palabra fýsis en las obras de Aristóteles (Bernabé, 2017) o la constatación de la igualdad que hizo Kahn entre ser y verdad (2009, p. 23 y ss.). Nuestra labor se amolda al desocultamiento en tanto hacer presente, mostrarse, sin que esto implique obviedad, porque lo que así se abre puede ser lo imposible, lo secreto, lo enigmático, lo equivocado, lo ausente, lo aparente, lo oculto. $Y$ es justamente sobre esta base donde se juegan no sólo las diferencias agonales entre los discursos sino también las maneras en que cada personaje se presenta, su aparición dramática (que no tiene por qué se clara y distinta).

Finalmente, cabe aclarar que el método escogido nos dispensa de considerar factores circunstanciales que hacen al drama en su totalidad, ya que el objetivo se alcanza mediante el procedimiento descripto. Por otro lado, tampoco existe una necesidad de analizar todos los discursos que componen al Banquete. Nos limitaremos al encomio de Fedro, Pausanias, Erixímaco y Sócrates, porque, si bien es cierto que la búsqueda caracterológica es menos compleja en los tres primeros (con lo cual las diferenciaciones ocurridas son un poco más entendibles), resultan suficientes para exponer lo que buscamos. Sin desmedro alguno, 
quedarán por fuera los discursos de Aristófanes, Agatón y de Alcibíades, por la sencilla razón de acotar el análisis a los límites de espacio de un artículo.

\section{Fedro, Pausanias y Erixímaco en su caracterización dramática}

\section{I. Fedro}

Una de las cualidades que resalta del encomio de Fedro, es la presencia de las fuentes culturales tradicionales: poetas y pensadores. En el inicio, son recordados Hesíodo, Acusilao y Parménides, $y$, por los ejemplos que utiliza en posteriormente, aparece también Homero. Reale, recurriendo a otros diálogos, lo caracteriza como un "literato para quien lo más importante es leer y saborear discursos escritos, y, por lo tanto, es un gran amante de los oradores y del arte de escribir" (1997, p. 20). Es decir que Fedro se muestra a través de su lógos como un conocedor de la cultura, una especie de sabihondo que utiliza esa misma sabiduría para justificar su comprensión de Eros (como también lo admite Reale).

Ahora, ¿cómo entiende a Eros? Fedro es el que primeramente sitúa a Eros en los fenómenos humanos, y es el primero de los invitados que dice de él que es un dios. Según lo caracteriza $(\mid 78 \mathrm{cl}-\mathrm{d} 4)$, Eros es quien rige en la relación educativo-pederasta entre el erastes y el paidion (el "educador-amante" y el "educado-amado") ${ }^{5}$. Es el responsable de crear-dentrode (empoiein) ellos la belleza (kalós) que los guía hacia (hegemonia) una vida digna (kalos biósesthai) y que les induce al rechazo de las acciones infames (aischrois), al producir el sentimiento de la vergüenza (aischýnen) ${ }^{6}$. Además, es el que implanta el deseo de esforzarse por la belleza; todo lo cual, asevera, es indispensable para lograr grandes y laudables acciones.

5 No traduciremos al español las palabras erastes, erómenos y paidíon, porque, como se verá a lo largo del artículo, depende del contexto, y aun así, su sentido nunca resulta definitivo. En cierto modo, todas las connotaciones juegan algún papel, siendo una más preponderante que las otras en algunos momentos. Podemos señalar que las dos primeras están obviamente vinculadas a éros, y, en un sentido general (con la intención de abarcar tanto como se pueda la multiplicidad semántica) el erastes es el que anhela y el erómenos es lo anhelado - así podrían derivarse: amante-amado, el que desea-deseado, el que quiere-lo querido, etc. Respecto del término paidiká, se lo puede entender como jóven o aprendiz, apareciendo así situado en una relación educativa, donde el educador es el erastes. Pero, en algunos discursos, como el de Pausanias, esta relación educativa está muy claramente rasgada por las características de un vínculo típicamente amoroso. Al respecto de la relación pederástica y su complejidad, sobre la que no nos detendremos, hay una amplia bibliografía. Creemos una excelente introducción el estudio realizado por Marrou en el capítulo III de su obra Historia de la educación en la Antigüedad (1985), donde expone su origen histórico, su función social, y las características que adopta tal relación. Interesa destacar, a los fines del trabajo, la siguiente afirmación: "[...] el amor [...] implica el deseo de

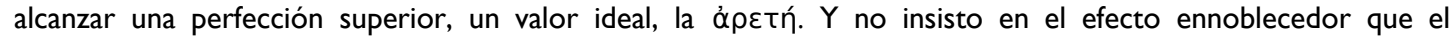
sentimiento de ser admirado puede ejercer sobre la persona de mayor edad, sobre el erasta; el aspecto educativo del vínculo amoroso concierne, sobre todo, evidentemente, al compañero más joven, al eromeno adolescente" (p. 5l). La nota siguiente es complementaria de esta. 


\section{JEREMÍAS CAMINO \\ Verdad, drama y filosofía en el Banquete de Platón}

Seguidamente, describe algunas de las situaciones en las que estas condiciones creadas por Eros intervienen para que cada uno de la relación pederasta alcance la virtud, que es importante revisar para obtener la actitud y la intención de Fedro.

Establece (178d4-e4), por un lado, que un erastes haciendo algo afrentoso sentiría una mayor pena si fuese descubierto por su paidíon. E igualmente en el caso inverso. A lo cual, Fedro añade (I78e4-I79al) que, si hubiera una ciudad o ejército formado por erastai y paidiká, no sería concebible que su gobierno hiciese cosas indignantes, ya que de eso aleja la belleza que implanta Eros, dándose, antes bien, un esfuerzo recíproco para conseguir las cosas honradas. llustra (179a4-8) esto con la situación en la que el paidion encuentre a su erastes dejando las armas, lo que le produciría el mayor sentimiento de vergüenza; o bien, la situación en que el erastes halle a su erốmenos en peligro, al que socorrería sin vacilación.

Sin embargo, a continuación, inopinadamente, Fedro establece (|79a4-bl) que Eros infunde (poiesei) la virtud, y rechaza la idea de que haya alguien que sea tan vil (kakós) para rehuirle y no llegue a ser virtuoso por semejanza a quien lo es por naturaleza. Pero, ¿quién es el virtuoso por naturaleza? Fedro había explicitado inicialmente que, lo mejor para un paidíon es tener un erastes virtuoso, por lo que cabría sospechar que aquí supone que aquel imitará a este. Incluso, Fedro sostiene explícitamente que los dioses dan gloria a los que hacen acciones hermosas $y$, por consiguiente, virtuosas, de manera tal que, el hecho de que el "educador-amante" muera por su "educado-amado" (179b4-5), nos invita a pensar que aquel es el virtuoso. Eso es lo que ilustra el ejemplo que da de Alcestis (I79b6-dI), y la razón por la que, al contrario, en el ejemplo de Orfeo, éste resulta castigado (I79d3-7). Sin embargo, Fedro da un tercer ejemplo que cambia el sentido de sus palabras: es el de Aquiles (179d8-180b6). Este es erốmenos, y resulta que los dioses lo congraciaron con la Isla de los Bienaventurados porque, argumenta Fedro, los dioses prefieren más a un erốmenos que se arriesga por su erastes que a la inversa.

Este giro dado al final de su encomio es decisivo. Aunque Fedro siga manteniendo la caracterización de Eros como un dios que crea la belleza en ellos a lo largo de su encomio (repite lo que dijo al comienzo en el final, en $\mid 80 \mathrm{bl}$ ) y sostenga, incluso, que hay una adquisición mutua de la virtud en la relación "educativo-pederastica", sin embargo, expresa que es más valorable la virtud que manifiesta el erómenos. Así, el modelo de virtud y de acciones

6 Escogemos estas traducciones respectivas para las diversas palabras griegas que aparecen en esta oración, de indudable importancia, basados en el contexto, pero también en la ambigüedad propia de kalós y su contraparte aischrois y aischryne. Dice C. Kahn al respecto: "En su uso clásico, kalós tiene un amplio rango de significados, y muchos de ellos se solapan con usos de agathós [...]; pero hay dos sentidos en los que kalós es distinto: por un lado, significa belleza física y, por otro, aprobación socio-moral, por eso puede traducirse a menudo por 'bello', y en otras circunstancias por 'admirable' y 'honorable', pero no así agathós" (2010, pp. 277-8). 
hermosas parece ser éste, quien debería ser, además, educador. Esto resulta relevante por cuanto Fedro es el erómenos de Erixímaco. Como dice Ludueña: "al fin y al cabo es el amado quien, con sus acciones naturalmente virtuosas, vale más. El discurso de Fedro [...] termina por elogiarse a sí mismo" (Platón, 2015, p. XLV).

La exhibición de sabiduría y la conclusión de la mayor valía del erómenos nos indican que Fedro se vanagloria a sí mismo. Asume su posición en la relación de pederastia, pero, en el fondo, no cree en ella, porque no necesita de una enseñanza. Lo que demuestra el encomio de Fedro es que él ya posee la sabiduría y, por lo tanto, puede enseñarla a los demás. Su intención principal es demostrar justamente eso a todos. De lo cual, se puede establecer que Fedro ostenta una actitud engreída y autosatisfecha.

\subsection{Pausanias}

Como dice Santa Cruz (201I, p. 19-20), con Pausanias se hace evidente por primera vez el sentido agonal del lógos. El personaje señala un error en la comprensión de lo que es Eros, transmitida por Fedro. Pausanias dice resolverlo introduciendo una diferenciación (180d4-5): Eros es un dios, pero no es único sino doble. La única razón que da de esto es lo que comúnmente se sabe ( $180 \mathrm{~d} 4)$, relativo al ser de Eros: que no hay (=no es) Eros sin Afrodita, y que hay dos Afroditas. La cualidad distintiva de las Afroditas también le corresponde a Eros. Así, dice, hay una Afrodita (y un Eros) uraniana, y una Afrodita (y un Eros) vulgar.

Hecha esta necesaria diferenciación comprensiva, Pausanias aclara: el elogio dependerá del alcance sobre las acciones humanas eróticas auspiciadas por cada Eros (180e4). Inmediatamente, introduce un supuesto general que parecería sustentar las afirmaciones más importantes de su encomio y que está entrelazado con tal división. Sostiene (180e4-|8|al) que la práxis en sí misma no es ni bella (venerable) ni vergonzosa, sino que lo es según el modo en que se la lleve a cabo. "Bellamente hecha, es decir, rectamente, devendrá [una acción] bella, no rectamente, [será] vergonzosa” (18la4-5). Así también será respecto de las acciones eróticas: sólo es valorativamente encomiable aquel enamoramiento (eran) que está conducido bellamente (kalós protrépon), es decir, por el Eros uraniano (I8la5-7).

Luego, introduce una serie de consideraciones breves sobre las acciones eróticas en general, que discrepa un poco con el criterio anunciado de bella acción. El Eros vulgar origina acciones caracterizadas por ser týche $(|8| \mathrm{l} \mid)$, es decir, azarosas, volubles, en una palabra, inconstantes. Esto significa que, el objeto de ese deseo y el medio para acceder es cualquiera, 
múltiple: mujeres y hombres, más los cuerpos que las almas, y si las almas tal vez, las no inteligentes (anoetotáton, I80bl-5). El Eros celestial, por el contrario, es selecto (patriarcal) con su objeto: sólo es de lo masculino, que "por naturaleza tiene más fuerza y es más inteligente [noun]" (I8|c7). Hecha la demarcación, Pausanias pasa a considerar la pederastia, en la que también aparece uno y otro Eros.

En la pederastia precedida por el Eros uraniano, dice, los erastai aman a los paidiká cuando éstos comienzan a tener inteligencia $(18 \mathrm{Id} 2)$. Por la contraposición antedicha, se concluye que, para Pausanias, la inteligencia es un objeto de amor no inconstante, de donde él deriva una relación de amor para toda la vida (182d5). En la pederastia vulgar, el erastes se vale de la condición afrosýne (inexperimentada) propia del paidión pueril (18Id6), para engañarle, utilizarle en su provecho, y luego abandonarle por otro. Tales relaciones, dice Pausanias, son ákairos kai adikós ( $18 \mathrm{Id7}$ ), intempestivas e injustas. Según esto, comenta, "algunos han osado afirmar que es vergonzoso complacer a los amantes" (182a2-3). Esta es la primera vez que aparece esta afirmación, y, de aquí en adelante, ocupará un lugar central. La intención de Pausanias será determinar en qué sentido es intempestiva e injusta, e intentará demostrar que las relaciones pederastas uranianas son lo contrario. De allí derivará la afirmación de que no es vergonzosa la complacencia de los amados.

En primer lugar, trata sobre lo que es justo en tales relaciones, y liga el sentido de lo que es justo al marco normativo (nómos) de los diferentes pueblos de la Hélade. Luego de comparar, a este respecto, otras ciudades, se detiene en su ciudad, Atenas. Anticipa que allí, las cuestiones del eros están mejor reglamentadas (nenomothétetai, I82d5), pero hay que saber interpretarlas. En Atenas, expresa, se considera más bello amar (éran) abiertamente (182d6-7), y más aún amar a los jóvenes de mejor linaje y más destacados (gennoaiotáton kai ariston, I82d7). Así, la búsqueda del amante no es ignominiosa (aischrón), y el logro es considerado honrado e infamante el no hacerlo. E incluso, en cuanto a cómo hacerlo, la norma prescribe hacer cosas increíbles (thaumastá, 182e2). Pero, si por dinero, poder u otra ventaja, alguien se somete en súplicas y ruegos, o se esclaviza a otro, tal como lo hacen los erastai por los paidiká, ello es contrario a la norma, según interpreta Pausanias. Por eso, los hombres y los dioses conceden la potestad (exousía) a los erastai pederastas de hacer cuanto quieran, siempre que deseen a los paidiká; y es eso lo que refleja, según dice, el nómos ateniense.

Respecto de si el amado debe dar satisfacción al amante, Pausanias, retomando la distinción inicial, dirá que: 
[lo realizado] deshonrosamente es la complacencia perversa a [un amante] perverso. [Lo realizado] decentemente, [en cambio, es complacer] decentemente a uno honrado. Perverso es aquel amante vulgar, que ama más el cuerpo que el alma, y que, como ama algo inconstante, no es constante. (I83d7-e2)

La primera afirmación habilita a pensar que puede haber una satisfacción realizada bellamente a un amante perverso, y la segunda que la satisfacción se realice malamente a un amante honrado. En base a esto, le importa a Pausanias determinar cuándo debe el paidión, si lo desea, congraciar al erastes (184b6): sólo cuando busca ser virtuoso. Y para ello, hay un solo camino

así como el sometimiento voluntario de los amantes a cualquier tipo de esclavitud por parte de sus amados no es considerado un acto de lisonjería ni es reprochable, del mismo modo, nuestra norma señala otro tipo de esclavitud voluntaria, una esclavitud singular, irreprochable: la que tiene por objetivo alcanzar la virtud [areten]. (|84cl-4)

Y así

cuando el amante y el amado, cada uno con su norma, apuntan hacia un mismo fin (uno al asistir al amado que lo complace en todo lo que sea justo [dikaíos], el otro servir a quien lo vuelve sabio y bueno [sofón te kai agathón] en todo lo que sea justo); y cuando el amante es capaz de contribuir en materia de sabiduría [frónesis] y de otras virtudes y el amado necesita procurar elementos para su educación y otros saberes [sofían], entonces las dos normas terminan por conformar una única. (I84d3el)

$\mathrm{Y}$ en ese momento es bello ( $\mathrm{y}$ justo) que el amante complazca al amado.

En el lógos de Pausanias, pues, se encuentran algunas cosas sorprendentes. Ante todo, es fácil deducir que, para éste, el "educador-amante" es el que, en la relación "educativopederasta", es más valorable y es modelo de virtud ${ }^{7}$. Ahora bien, siendo él el erastes de Agatón, y que, según estableció, le importa, en tanto educador, el entendimiento (nous) del educado (paidión) y que éste se vuelva experimentado y virtuoso (sofón kai agathón), ¿cuál es la razón de demostrar que la complacencia de este a aquel sea un buen acto y así forzar la interpretación de la norma ateniense?, ¿qué significa la experiencia y la virtud del educador cuando le interesa que el educado le devuelva en favores su educación?, ‘acaso no se traba así un comercio? Por otro lado, ¿qué significa ser inteligente, sabio y bueno, cuando el "educador-

7 Ésta vendría a ser una crítica implícita al encomio de Fedro, para quien la situación era inversa. 


\section{JEREMÍAS CAMINO \\ Verdad, drama y filosofía en el Banquete de Platón}

amante" y el "educado-amado", en su relación, se vuelven voluntariamente esclavos uno de otro?, ¿qué tiene de buena una educación que hace dependiente al educado del educador?, ¿no confronta ello con la libertad del ciudadano griego? Esto se torna aún más acuciante por cuanto, como señala hacia el final, es bello que el amado complazca bellamente a un amante perverso, que se descubre que no era virtuoso, porque el paidión buscaba la virtud: jacaso no era el modo de realización lo que tornaba bella la acción? ¿Qué significa aquí belleza (honradez)?, ¿puede una acción loable conducir al engaño? Todo esto no pareciera jugar a favor de autoelevación como educador.

Estas preguntas nos señalan que, detrás del encomio de Pausanias, se esconde un deseo vivo por que Agatón sea condescendiente con él, y que esto sea finalmente aceptado por los demás. Se podría tener una medida de la intensidad de este deseo, por un lado, por el espacio mayoritario que ocupa en su discurso la cuestión de que el amado sea condescendiente, y por el otro, por el esfuerzo que le demanda una argumentación casi imposible para persuadir a los demás. Esta casi imposibilidad fue bien observada por Neuman (1964, p. 266): combina dos aspectos opuestos de la moral ateniense (educar moral y filosóficamente a los jóvenes y la prohibición de consentir del amado). Por lo cual, se manifiesta a través de su lógos un personaje tensionado entre su deseo interno y el marco normativo y la opinión pública. Como estos dos encorsetan a aquel, el deseo no puede ser satisfecho, y así lo tiene sujetado, esclavizado ${ }^{8}$. Esto, sumado a que el lógos está construido de una forma argumentativamente contradictoria (la definición de acción bella es contradicha en varios momentos donde prevalece el objeto y no el modo) y afirmando cosas poco aceptables por la comunidad y sorprendentes (como la esclavitud erótica), se demuestra que está afectado por una preocupación que le lleva a construir un encomio que justifica una situación (imaginada) en la que su deseo está finalmente resuelto a su favor. Preocupado, insatisfecho, contrariado

8 Neumann interpreta esta insatisfacción del deseo como una carencia, lo que le permite ligarlo directamente al discurso de Diotima. La propuesta es lógica, y resulta interesante porque concluye que Pausanias ama de Agatón la juventud y la belleza de la que carece (es ya adulto), negándose así a su propia realidad y al deseo de inmortalidad. Una patología (1964, p. 266) que demuestra, pues, temor a la muerte. Esta interpretación tiene en contra justamente lo que sustenta tales conclusiones: analizar psicológicamente a Pausanias según la comprensión de Sócrates. Esto sólo se puede justificar si Platón, autor de la obra, entiende así la psicología humana y pretende que ello sea percibido en cada personaje. Pero, además de que esto habría que cotejarlo con otras obras donde aparecen "análisis psicológicos", es discutible en función de que tal psicología no es explícita en cada uno de los discursos, y, además, cabe la posibilidad de que su intención, en tanto escritor, sólo sea presentar característicamente a los personajes en su "inmediatez", lo que deja un espacio al juicio del lector el sopesar entre las diferentes actitudes. 
socialmente: Pausanias se muestra a través de su lógos como alguien dolido, mejor dicho, herido?.

\subsection{Erixímaco}

Erixímaco sigue con el sentido agonal del lógos (Santa Cruz, 20I I, p. 20); pero, a diferencia de los otros dos, presenta un encomio más rígidamente estructurado, una comprensiónepistemológica en un sentido que abarca más allá de las acciones humanas. Erixímico afirma: Eros está en muchas cosas (en polla estín). Y enumera: en el alma humana de los jóvenes bellos, en los cuerpos de animales, en todo lo que surge en la tierra; en fin, "en todo lo que es" (186a7). En el decir de Hua-kuei Ho (2013, p. 183): "continua con la distinción de Pausanias [...] pero extiende la tesis a todo el universo. [...] Erixímaco traslada la distinción dentro de un lenguaje más científico, conteniendo una explicación más racional desde la perspectiva de un practicante de la medicina".

Por un lado, la explicación racional, nos dice Hua-kuei (p. 184), sigue la tradición hipocrática de proveer su propia explicación (lógos) de las cosas, a la que Erixímaco construye con la armonía de los elementos. A este respecto, consideramos correcta y suficiente la exposición ofrecida por Laura Candiotto en las secciones "The cosmological role of harmony" y "The composition of elements" de su artículo "The concept of harmony (187a-e) and its cosmological role in Eryximachus' discourse" (2013). Por otro lado, la medicina, según Huakuei amparándose en su lectura de los primeros diálogos platónicos, ya era tenida por Platón como una téchne y un "típico modelo de conocimiento" (p. 184), es decir, una episteme.

Ahora bien, esta última apreciación de Platón, sumada a la exposición de un lógos en tanto explicación fundamentada, y la armonía de los elementos como conceptualización epistemológica que, según Hua-Kuei, también tiene una valoración positiva en Platón (ya que la encuentra, correctamente, en República), todo ello, decimos, hace un conjunto de afinidades entre el encomio de Erixímaco y el pensamiento platónico, de tal modo que, Hua-kei (y otros) concluye que es incorrecta una tesis que prevaleció hasta mediados del $\mathrm{S}$. XX sobre el personaje de Erixímaco: una caricatura de doctor de la pedantería experta y científica (p. 183). Sobre este punto quisiéramos detenernos, en relación a los fines del trabajo.

9 Éste es uno de los aspectos negativos de una relación amorosa que no es reflejado por el Eros vulgar. Los comportamientos que exhibe un individuo afectado negativamente por Eros (incluso, el pretendidamente uraniano por Pausanias) ya habían sido dramatizados ejemplarmente por Sófocles: a este respecto Douterelo (1997). 
Según esa línea de razonamiento, que se sale de las inmediaciones del lógos de Erixímaco, la conclusión antedicha es correcta. Sin embargo, el punto de partida para una caracterología debería ser el mismo lógos. Erixímaco pretende captar en Eros un punto de vista katheorakénai (I86a7), que se lo atribuye como cualidad al dios. Antes de traducir esa palabra, enfaticemos en el movimiento que realiza Erixímaco para ir desde la comprensión de Pausanias a la suya: un paso efectuado no sólo desde la medicina (hek tes iatrikes l86bl) sino

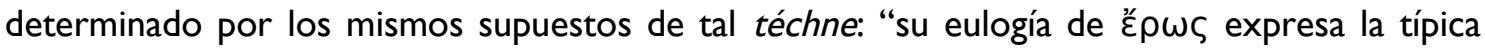
perspectiva de la medicina griega que enfatiza la armonía entre diferentes elementos e intenta conseguir la salud del cuerpo y el alma (I85e-188e)" (Hua-kei Ho, 20I5, p. I85). La razón que encontramos de esta afirmación es que Erixímaco, en su comprensión de lo que es Eros, traspasa los supuestos de su téchne a pasi tois ousi, una proyección que le lleva a tener una visual-por-encima (katheorakénai) de cada ente, una mirada abarcadora de la totalidad. Su juego es una inversión: encuentra en Eros lo universal porque, antes, proyectó la comprensión específica de una téchne, sobreponiéndola a la totalidad. Su intención es presentar al conocimiento médico como universal. Erixímaco, como todo "científico", es un pretencioso. Los diversos ejemplos de ciencias igualmente específicas que trae, tienden a confirmar su tesis, porque ya decidió de antemano que así sería: ya lo previó y así armó su discurso. Esa es la razón por la que su encomio posee una articulación y un principio que es articulante, basal y determinista. Su lógos se presenta como un conocimiento ya consumado (téleios) y así es como muestra a su expositor: el que ya sabe con una actitud marcada por la presunción, una persona completamente formada ${ }^{10}$.

De hecho, Erixímaco, anticipándose a su momento expositivo, apareció con el típico comportamiento de un presuntuoso: tomando el lugar de archós del simposio y recetando el modo de curar el hipo de Aristófanes, Erixímaco desea y busca mostrarse a los demás como el sobresaliente, ser el primero, con una comprensión de las cosas lógica y eficiente, y de inmejorables propuestas. Es este carácter y cierto halo de vanidad, el que percibe claramente Aristófanes, y por eso, no sólo se burla de él, sino que además crea un discurso antitético con el de aquel: si Erixímaco, en base a un supuesto (el de la medicina), presentó un discurso lógico ya elaborado, Aristófanes, en cambio, improvisará el suyo en la forma de un mito, igualmente apropiado para la comprensión de Eros.

10 Se puede notar que esta cualidad es común, según hemos intentado justificar, a Erixímaco (educador en la pederastia) y a Fedro (educado en la pederastia). 


\section{El lógos de la filosofía}

\section{I. Repaso de los resultados más importantes}

Creemos que, con lo anterior, se fue demostrando la reciprocidad existente entre el lógos pronunciado y la mostración del personaje. Fedro aparece autosatisfecho en la creencia de su posesión del saber, Erixímaco se presenta presumiendo de un conocimiento científico completo de la totalidad, $y$, finalmente, Pausanias adoleciendo de una tensión que intenta demostrar como resoluble y manejable. Por otro lado, en todos los casos encontramos que el lógos expuesto exhibe al personaje buscando, no sólo una aceptación de los demás, sino aquello que Santa Cruz señala: "proteger y mejorar" su presencia ante al resto y un temor a ser reprobado. Así, podría reunirse lo anterior en tres aspectos, que resultará importante para la siguiente tarea: A) Cada uno quiere mostrarse como siendo bello a su manera, esto es, que Eros le haya imbuido de su poder, en lo que cada uno cree que es ser bello. Pues, belleza es (descontando su sentido físico) la forma magnífica de la aceptación social "'; B) Cada uno quiere mostrarse como autor y, por consiguiente, portador de eso que lo hace ser bello, lo cual está mostrado en el lógos que expresa; $y$, finalmente, C) Cada uno aparece teniendo todo lo que necesita: sabiduría o conocimiento de las cuestiones eróticas ( $y$, por lo tanto, de la belleza) e inteligencia para manejarse en tales cuestiones ( $y$, por lo tanto, en la belleza).

Establecidos estos puntos, pasamos ahora a la caracterización del personaje Sócrates según aquello que él dice, para luego, finalmente, hacer una especie de balance de las diferencias entre los discursos anteriores y el de la filosofía.

\subsection{El lógos de la filosofía, el filósofo y la paideía filosófica}

Sócrates es parte del tercer y último agón (Santa Cruz, 20II, p. 22 y ss.), y su referencia más inmediata, por ello, es Agatón. Según el contenido positivo de su intervención, el modo de expresión inicial es la ironía: el encomio de Agatón fue algo asombroso (thaumastos), "un lógos dicho [de un modo] bello [kalon] y florido" (198b3). Kalós aquí connota, sin duda, exhibición, un encantar y agradar a los oyentes: en ese sentido, y medido por la repercusión de

II Esto parece evidente en Fedro y Pausanias; pero, también lo es en Erixímaco: pues, no sólo es el paladín de la salud, de lo cual debería ser un ejemplo, sino que sabe que la salud es deseada por la mayoría. Esta es la vara con la que se mide a él y al resto, y el trampolín de su alta estima hacia sí. 
su discurso ("todos los presentes lo aclamaron", 198al-2), Agatón es un ejemplo sobresaliente de los cinco encomios sucedidos. Por ello entendemos que, lo que Sócrates dice de éste, también vale para todos los demás. Él declara, sin embargo, que ése no es su objetivo, sino otro: pronunciar un talethes légein (198d3-4), al que no considera como un encomio (199a6).

Ahora bien, hemos expuesto al comienzo de este trabajo que la función del lógos ya es aletheúein, por lo que el Sócrates platónico no estaría presentando nada nuevo en ese sentido. Socrates contrapone el lógos alethous al lógos pseydes (198e2), lo que se decide en atención a lo tematizado (198d4-5), esto es, según aquello que el pragma (ti legómenon) sea o no (échonta te me, 198el-2). Así pues, la pretensión explícita del discurso filosófico (alcanzar el lógos alethous) es presentar lo tematizado tal como se muestra; en otras palabras, decir de algo aquello que es tal como es. Sin embargo, como hemos desarrollado, los otros encomios también han presentado una comprensión de Eros en la que se pretendió mostrar lo que este es. ¿Por qué, entonces, son desestimados por el personaje Sócrates? Porque en ellos, dice, Eros fue desocultado como lo que parecía ser (lo doxázontos, 198e4), de modo tal que, mostrándolo (faínethai, 198al) como bellísimo y destacado, también así se manifestaba (delon) el propio encomio (198a3). En estos, pues, el lógos es pseyde, lo cual no significa ser falso (como contemporáneamente se lo interpreta), sino equivocado. Aquí equivocar significa desviarse del camino, de forma tal que aquellos encomios proclamaron apuntar hacia el objeto encomiado $y$, en su marcha, se orientaron al propio discurso. En otras palabras, Sócrates denuncia que fue producida una imagen que parecía ser Eros como tal, con el fin de generar una opinión favorable de la mayoría sobre el encomiasta. Frente a esto, ocurre la filosofía. Para satisfacer la pretensión de esta, se requiere atender y atenerse a la cosa misma que es tematizada, lo que sólo se logra con una conducta y acción concordes.

Para lograr esa meta, hay dos factores íntimamente entrelazados que el discurso filosófico propone. En primer lugar, la forma en que procede es el diálogo (dialégesthai). J. J. Cleary lo ha señalado ( $y$ demostrado) correctamente:

Ha de notarse que no sólo esta parte de la contribución socrática [el intercambio inicial entre Sócrates y Agatón] sino una porción significativa del reporte de la enseñanza de Diotima, sigue el formato de pregunta-y-respuesta, en el cual Sócrates reemplaza a Agatón en el lugar del que responde. (2007, p. 34)

En el intercambio entre Sócrates y Agatón, y entre Diotima y Sócrates, el que pregunta ya sabe algo del tema sobre el que dialogan, y el que responde aprende y acepta lo que se va diciendo (dependiendo de si comprende o no, de si sabe o no, o de si tiene una consideración 
diferente o no). Hay una especie de construcción mutua, en el sentido de compartir el camino de indagación para intentar concordar en lo que es aquello de lo que tratan juntamente, siendo el que pregunta una especie de guía (Sócrates, en 177d7-8, declaró saber de erótica, y Diotima es una sofe de esas y muchas otras cosas, 20Id3).

Por otro lado, el punto de partida del lógos filosófico es el problema, que debe ser preparado en función de la meta y el modo de alcanzarla. El problema que plantea la filosofía es el de un no saber qué es algo, sin que, por ello, se constituya en desconocimiento (amathía). Esto significa que ya se sabe que algo es lo tematizado, en otras palabras, que está abierto a través de cierta comprensión sobre la cual la filosofía realiza su propio trabajo ${ }^{12}$. Hay un sentido más fácil e inmediato de identificar qué constituye esta comprensión, y es la que ofrece el encomio de Agatón - aunque cabe suponer que todos los discursos anteriores son contribuyentes en cuanto han desocultado a Eros de algún modo. Pero también hay un sentido menos visible ligado más estrechamente al carácter de apertura, en el que tendremos ocasión de ahondar en breve. Por ahora, importa dejar establecido que el problema que plantea la filosofía surge porque se reconoce una carencia (endees) o una no posesión (oude échei). Y ¿de qué se está carente o falto? Justamente, de un lógos alethes (202a5), un lógos que, en su aspecto filosófico, es una comprensión dialógica orientada hacia el desocultamiento (la verdad) de Eros: de su propio ser.

Resulta bastante evidente que estas condiciones del lógos filosófico son hallables en el comportamiento o carácter del filósofo $y$, en particular, en el personaje central de Platón: Sócrates $^{13}$. Esta caracterización aparece explícitamente en el relato que Sócrates interpone o recuerda: su intercambio con la sacerdotisa Diotima. El contenido de esta conversación presenta al daimónion Eros como una imagen poética de lo que es el filósofo. Según esto último, Diotima anoticia a Sócrates de que Eros, no siendo ni bueno ni bello (20 le6-7), desea aquello que le falta (202dl-3), condición que no es propia de un dios (que es bello y bueno), pero tampoco de un mortal. Así, Eros se muestra como algo intermedio entre uno y otro (202d I I), comunicando a los hombres y los dioses (203e3-4), y uniendo a la totalidad consigo misma (202e6-7). Por su genealogía (203b I-204a7), “en un mismo día, por momentos florece y

12 Lo tematizado problemáticamente parte de saber que algo es; tal saber, o bien puede ser un supuesto derivado del mero hecho de tenerlo por algo ( $y$, a la vez, decirlo, nombrarlo, referirlo), o bien de una opinión sobre la que debe ahondarse (por diversos motivos: ya porque tiene algo equivocado, ya porque no es clara, etc.). Ha de notarse que Sócrates asumió, ante Diotima, que tenía una concepción sobre Eros como la de Agatón, que era una opinión equivocada.

13 Lo primero que Sócrates enuncia es su intención: "Por tanto, considerá, Fedro, si hace falta un discurso semejante, [si hace falta] escuchar un lógos verdadero acerca del eros" (199b2-4), y lo primero que hace es dialogar con Agatón, con el fin de hallar qué es éros. 
vive, pleno de recursos, y por momentos desfallece; pero revive por la naturaleza paterna, aunque sus recursos estén en continuo alejamiento" (203el). Eros, a la vez, "siempre está urdiendo alguna trama $y$, deseoso de sabiduría [fróneesis] e ingenio, se pasa la vida filosofando; es un mago tremendo, un hechicero, un sofista" (203d6-8).

Respecto de la sofía y de la amathía, Eros "está en medio" (204al). A este respecto, dice Diotima:

Ninguno de los dioses filosofa ni desea llegar a ser sabio, pues ya lo son, ni van hacia la sabiduría [sofía], sino [sólo] el que filosofa. Pero tampoco los que desconocen [amatheis] filosofan, ni desean llegar a ser sabios. Eso es lo penoso del desconocimiento, el no ser bello y bueno ni sabio [frónimon], y parecer serlo suficientemente: quien no se considera a sí mismo estar carente de algo, no se muestra deseando lo que considera que no le falta. (204al-7)

Eros y el filósofo humano se solapan: así como aquel, no siendo un dios ni un mortal, está orientado hacia los dioses (que son bellos y buenos), el filósofo humano, no siendo un sabio ni un ignorante, está orientado hacia la sabiduría (204bl-2), que, por este parangón, es algo divino.

Es importante enfatizar que esta comprensión que el personaje Sócrates presenta a través de Diotima, pone a la belleza como algo a lo que Eros aspira - diferentemente, los otros encomios lo presentan como responsable de la belleza (es decir, lo virtuoso y lo loable) porque él mismo lo es. La imagen poética de la filosofía trae consigo que, el erómenos del filósofo, es la sabiduría (sofía), en otras palabras, la belleza a la que aspira el filósofo es el saber. Lo que sea la sabiduría nunca se dice porque, como la belleza, es un secreto. No obstante, según discurre el lógos de Sócrates, la sabiduría está en un ámbito que no es el de las cosas habituales humanas, lo que envuelve un tipo de interés y de comportamiento que diferencia al filósofo del resto. Si pretendemos entender la conducta y la comprensión filosófica, debemos apuntar a esa misma diferencia. $Y$ resulta que, tanto el interés como la comprensión y el comportamiento filosóficos, son generados por la paideía filosófica.

Para entender correctamente la paideía filosófica, debemos comenzar con una pregunta que, según el relato de Sócrates, le hace éste a la sacerdotisa Diotima: ¿para qué sirve Eros a los humanos? (204d4), a lo que ella le repregunta: ¿qué es la belleza a la que el daimónion Eros aspira?, en otras palabras, ¿qué es el que deviene (genésthai) bello? Como Sócrates no puede responder a esto, hacen un "rodeo" para alcanzar la respuesta a través de la noción de bondad (204e5-7), que resulta un poco más sencillo. Así el desear (éran) ser bueno sirve para ser feliz 
(eudaimonía), que es el modo más propio de ser. Además, Diotima y Sócrates concuerdan en que se desea serlo permanentemente (aei). Esta necesidad de permanencia surge porque el ente humano está continuamente tensionado entre el ser y el dejar de ser, es decir, el estar ante la continua recaída en el no ser, que corresponde a los entes generados - aquellos que no han sido y que dejarán de $\operatorname{ser}^{14}$. El tipo de acción y esfuerzo que deben hacer quienes desean ser buenos, proclama Diotima (206b7-8), es el engendrar en lo bello, tanto con el cuerpo como con el alma. Tal es la forma que elucubraron los mortales, dice, para resguardarse (sózetai: 208a8) en su ser. Diotima hace alusión a los diferentes tipos de engendramiento según los géneros de vida (animal no humano y humano) y los tipos especíicos (o biografía) en la vida humana, de las cuales nos interesará aquí la que incumbe a la filosofía.

El engendrar en lo bello en el camino de la filosofía comienza por un estar preñado (egkúmones), un ya estar henchido (kuon) en el alma del joven, que lo lleva a buscar y a vincularse (209a3) con aquello con lo que el alma está emparentada (prosekei): las cosas que son bellas (209b3). El contacto con estas moviliza al aprendiz a la creación espontánea de lógos. En 206dl-2, Diotima había anticipado que debe haber allí una armonía, en el sentido de un ajustamiento entre las cosas que ya están entrelazadas. Todo esto significa, en primer lugar, que lo que se muestra como bello ("las cosas bellas") se desocultan como tales para quien, a su vez, ya tiene la disposición a desocultarlas como bellas. Se engendra cada vez una comprensión (lógos) en el sentido de un reconocer, de un tomar lo que se abre como tal: en otras palabras, de estimar lo bello en tanto bello. Por esto, no puede haber nunca una amathía, un no tenerlo aprendido, pues ya lo tiene como tal en un cierto grado. En segundo lugar, el joven ya posee, por así decir, una especie de "guía interna", un presentir lo que se presenta. Sin embargo, el joven, a la vez, requiere de un guía exterior (el filósofo) que le ayudará a afianzar y aguzar aquella comprensión (lógos). Esta relación entre el joven y su conductor se funda en que ambos armonizan (209b7) en tanto están ya orientados hacia lo mismo. Por eso, Diotima le dice a Sócrates: "al estar [el joven] en contacto con el que es bello y tratarle [esto es, con el filósofo educador], según pienso, concibe y engendra lo que ya hacía tiempo había concebido" (209c3-4). Ambos se unen (209b7) para nutrir, para hacer emerger, esa

\footnotetext{
I4 En estas tres oraciones, hemos simplificado una idea que se puede hacer más clara con lo que sigue en el trabajo. Anticipando un poco esa lectura, conviene hacer una breve indicación sobre los conceptos involucrados (kalós, agathós y eudaímonía) en el sentido filosófico en que creemos que Platón los emplea aquí. Estos tres se encuentran relacionados de un modo inexplícito en el Banquete. Como hemos explicado, la palabra eudaímonía, que los latinos tradujeron como felicitas, puede entenderse como significando un seguir rectamente aquello a lo que propiamente se tiende, esto es, aquello que conduce a la realización de lo que es. En ese sentido, lograr tal anhelo implica una culminación o cumplimentación correcta de lo que debía ser, cumpliendo, así, su designio. A esto se lo llama agathós, que los latinos tradujeron como bonus, el bien, lo excelente. Lo que más adelante denominaremos erótica filosófica se ocupa justmente de este anhelo.
} 
comprensión que comparten.

Así pues, el joven aprendiz va desocultando lo bello como tal, tanto como se va desocultando para sí mismo lo que ya colma su alma, esto es, su ser. En la comprensión cada vez mayor de la belleza de las cosas, va comprendiéndose a sí mismo como filósofo, va encausando y cumpliendo su anhelo interno. Por lo tanto, la belleza en tanto verdad de Eros se manifiesta en el filósofo como un desocultarse a sí mismo desocultando con mayor profundidad cada vez aquello a lo que está orientado naturalmente, esto es, aquello que le nace ser. Podemos resumir todo esto en la afirmación: la verdad de eros es el ser.

En el camino de la filosofía, pues, el filósofo se presenta como aquél que aspira a tener una comprensión (lógos) de la belleza, esto es, que busca aprehender la sabiduría. Esto es lo que Diotima describe en el pasaje que se conoce como ascenso (209e5-2I2a5). Pasando por los cuerpos y almas bellas, las bellas costumbres y leyes, a través de las bellas virtudes y los bellos conocimientos, el aprendiz llega a estar frente al múltiple mar de lo bello, momento en el cual, repentinamente, la belleza misma se presenta y es captada por el filósofo. Tal es la forma en que aprehende cómo todo lo demás participa de ella para llegar a ser lo que es (=bello). Lo que así se pone de manifiesto es que la belleza (sabiduría) es la que genera una comunidad entre el aprendiz y el filósofo guía, a la que ambos aspiran y desean contemplar (esto es, ser), y que da valor a la vida humana ( $2 \mathrm{I}$ Idl-3), es decir, que da vida al que desea ser filósofo ${ }^{15}$. Por lo tanto, a pesar de comenzar en las cosas bellas que forman parte de la totalidad de las cosas humanas habituales, el filósofo está interesado por algo que no está allí, pero que, no obstante, le determina. Razón por la cual, el filósofo educador y el filósofo aprendiz no buscarán ni los favores amantes del otro, ni tampoco la fama social ${ }^{16}$, sino algo "más allá" que justifica, en gran medida, su caracterización como divino. El drama de la filosofía no está en la habitualidad del mundo humano.

I5 A este respecto, C. Kahn, bajo la tesis de que lo bello es lo bueno (20I0, p. 279), explica que el deseo (éros) es "un caso especial del deseo humano universal hacia las cosas buenas (205a, d). [...] El eros platónico es simplemente la forma más intensa de ese deseo profundo de bien ( $y$ en última instancia del Bien) que anima todas las almas humanas. Este deseo puede torcer su rumbo, pero tiene en sí mismo un mecanismo de orientación que apunta a lo naturalmente bueno, querido (philon) y deseable. Según Platón, lo que le ocurre al filósofo cuando asciende por la escala del amor, y lo que se expresa en República VI como reencauzamiento del deseo, es primero y ante todo el redireccionamiento del deseo racional, nuestro deseo de lo bueno-y-bello, que deja de perseguir un blanco equivocado y se encamina a su propio objeto" (Kahn, 2010, p. 287).

16 Obviamente, esta caracterización queda en un suspenso extrañísimo por la presencia de Alcibíades, que es una de las grandes incógnitas de la exposición tan bien acabada del discurso de Sócrates: un muchacho que se mostraba teniendo todas las cualidades "naturales" para ser filósofo, educado por el propio Sócrates, y que, sin embargo, no logra superar las etapas primeras del ascenso a la belleza, que demuestra en su encomio de Sócrates de manera tan pasional. Se podría llegar a sostener que la presencia de aquel eclipsa (=oculta) al discurso desocultante de éste. Como sea, el enigma queda planteado. 
En conclusión, la erótica filosófica es el intento continuo de desocultamiento (verdad) de lo que hace ser a todas y cada una de las cosas que son tenidas por bellas. El deseo filosófico sostiene la permanencia en tal actitud, que motiva una ejercitación recurrente y refleja un anhelo de llegar a alcanzar aquello que siempre contempla, y que se encuentra más allá de las cosas habituales humanas.

\section{Balance final}

Siguiendo la interpretación heideggeriana de la verdad en la filosofía de Platón, hemos mostrado, primeramente, cómo el lógos de varios personajes del Banquete es un reflejo del carácter del personaje. Dentro del campo agónico, terreno donde mejor crece la semilla filosófica, hemos mostrado que el discurso filosófico no es tanto la pretensión de apresar mejor los hechos, sino de hacer más fuerte y explícita la función desocultante (aletheúein) del lógos. Los encomios anteriores al de Sócrates mostraron a Eros mediante la producción de una imagen de Eros, cuyo fin fue desocultar de modo elevado la presencia del propio encomiasta. Esto implicó, sin embargo, el ocultamiento de la intención real del encomiasta. Frente a ello, el discurso filosófico denuncia un ocultamiento ulterior, punto central de su disputa: tales encomios demostraron un ocultamiento de lo que es Eros. Así, se elabora una comprensión que desoculta doblemente: tanto a Eros como al filósofo, mediante la producción de una imagen poética. A su vez, el discurso filosófico pretende distinguirse en cuanto a lo que ella persigue: si aquellos buscaban una belleza en el sentido de la aprobación social, que es cambiante y múltiple, en cambio, la filosofía aspira a lo que ella postula como algo que es en sí mismo, incambiable, siempre igual a sí mismo, y único. Frente a la belleza que los encomiastas proclaman haber adquirido, el filósofo mantiene en un suspenso misterioso el que, si alguna vez la alcanza o no, que, no obstante, afirma estar siempre contemplando ( $y$, por lo tanto, en una relación que le permite alcanzarla). No deja de resultar interesante lo siguiente: el objeto de interés de los encomiastas no filosóficos es la aprobación pública, que está expuesta, exhibida, y está siempre aquí, entre las cosas habituales y humanas; en cambio, el objeto de interés del filósofo, por más que esté nombrado y caracterizado como lo responsable de la entidad de las cosas bellas, sigue siendo, no obstante, algo que no se exhibe, sino que permanece en el ocultamiento propio de las cosas secretas. Esto es así porque siempre es posible preguntar qué significa que la belleza sea la causa de las cosas bellas, qué es y cómo es eso que Diotima ha visto, cómo es que se da su captación repentina extra "lógica". Situación que reanuda 
continuamente la investigación sobre lo que hace ser bellas a las cosas, y que, en última instancia, es reflejo de la persistencia filosófica de seguir preguntando una vez más.

\section{Referencias}

Bernabé Pajares, A. (2017). En torno a la phýsis. ¿Qué entendían los griegos por physikós? Archai, 2I, 39-78.

Candiotto, L. (2013). The concept of harmony (187a-e) and its cosmological role in Eryximachus' discourse. Proceedings of $X$ Symposium Platonicum (Vol I). Universitá di Pisa.

Cleary, J. J. (2007). Erotic Paideia in Plato's Symposium. En M. Erler \& L. Brisson (Eds.), Gorgias - Menon. Selected papers from the seventh Symposium Platonicum. Academia Verlag.

Douterelo, E. (1997). El léxico y el tema del amor en Las Traquinias de Sófocles. Cuadernos de Filología Clásica. Estudios Griegos e Indoeuropeos, 7, 195-206.

Hua-kuei, H. (2013), 'Eryximachus' medicine in the Symposium and Plato's Love. En Proceedings of $X$ Symposium Platonicum (Vol. I). Universita di Pisa.

Heidegger, M. (1976). Logik. Die Frage nach der Warheit. Vittorio Klostermann.

Heidegger, M. (1992). Plato: Sophistes. Vittorio Klostermann.

Kahn, Ch. (2009). Essays on Being. Oxford University Press.

Kahn, Ch. (20I0). Platón y el diálogo socrático. El uso filosófico de una forma literaria. Escolar y Mayo.

Marrou, H. I. (1985), Historia de la educación en la Antigüedad. Akal.

Neuman, H. (1964). On the sophistry of Plato's Pausanias. Transactions and Proceedings of the American Philological Association, 95.

Platón (1957). Platonis Opera (Vol. 2). Oxford.

Platón (1938), Le Banquet. En Ouvres Complètes (Vol 4). Les Belles Lettres.

Platón (2007), Le Banquet. Flammarion.

Platón (2015), Banquete. Colihue.

Reale, G. (1997). Eros, Demonio Mediador. El juego de las máscaras en el Banquete de Platón. Herder.

Santa Cruz, M. I. (201 I). Un simposio y tres agones: una lectura del Banquete de Platón. Kléos, $15,9-25$. 